\title{
Justiça Organizacional: Análise Empírica da Percepção de Bancários do Setor Público e Privado ${ }^{1}$
}

\section{Organizational Justice: An Empirical Analysis of the Perception of Bank Employees in the Public and Private Sector}

\author{
Tarízi Cioccari Gomes ${ }^{1}$ \\ Vania de Fátima Barros Estivalete ${ }^{2}$ \\ Amanda Oliveira Ramadam ${ }^{3}$
}

\begin{abstract}
Resumo
O propósito deste estudo foi analisar a percepção de justiça organizacional segundo os colaboradores que atuam em bancos públicos e privados de uma cidade do interior do estado do Rio Grande do Sul, no Brasil. Para alcançar esse objetivo, participaram da pesquisa 339 trabalhadores das organizações do setor bancário público e privado dessa cidade. $O$ método de pesquisa adotado foi quantitativo, utilizando-se como instrumento de pesquisa o questionário estruturado validado de Mendonça, Pereira, Tamayo e Paz (2003), denominado Escala de Percepção de Justiça Organizacional. Os resultados deste estudo demonstraram que há maior percepção de justiça em bancos privados. Por outro lado, foi identificado que, em ambos os setores, houve maior percepção de justiça na dimensão interacional. Dessa forma, sugere-se uma maior preocupação dos gestores em relação às práticas organizacionais, a fim de obter melhoria na percepção de justiça dos colaboradores e evitar problemas futuros decorrentes dessa constatação.
\end{abstract}

Palavras-chave: justiça organizacional; bancos; percepção; colaboradores.

\begin{abstract}
The purpose of this study was to analyze the perception of organizational justice according to employees who work in public and private banks in a city in the interior of the state of Rio Grande do Sul, in Brazil. To achieve this objective, 339 workers from public and private banking organizations in this city participated in the survey. The research method adopted was quantitative, using the structured questionnaire validated by Mendonça, Pereira, Tamayo, and Paz (2003), called Organizational Justice Perception Scale, as a research instrument. The results of this study demonstrated that there is a higher perception of justice in private banks. On the other hand, it identified that, in both sectors, there was a higher perception of justice in the interactional dimension. Thus, it is suggested a greater concern from the managers regarding practices to obtain improvement in the perception of employees' fairness and avoid future problems arising from this finding.
\end{abstract}

Keywords: organizational justice; banks; perception; collaborators.

$\overline{1}$ Trabalho apoiado pelo Programa Institucional de Incentivo à Qualificação Profissional dos servidores do Instituto Federal Farroupilha (PIIQP) e pelo Conselho Nacional de Desenvolvimento Científico e Tecnológico (CNPq).

9 Doutoranda do Programa de Pós-Graduação em Administração (PPGA) da Universidade Federal de Santa Maria (UFSM). Faz parte do grupo de pesquisa COESIS - Comportamento Organizacional, Empreendedorismo e Inovação Social (UFSM).

(9) Pós-Doutorado em Sociologia Econômica das Organizações no SOCIUS - Centro de Investigação em Sociologia Econômica e das Organizações no ISEG - Instituto Superior de Economia e Gestão da Universidade de Lisboa-Portugal. Professora associada do Departamento de Ciências Administrativas da Universidade Federal de Santa Maria. grupo de pesquisa COESIS - Comportamento Organizacional, Empreendedorismo e Inovação Social (PPGA/UFSM). 


\section{INTRODUÇÃO}

A percepção de justiça nas organizações permeia todas as esferas, tanto públicas quanto privadas. Essa percepção pode fazer com que os colaboradores se sintam mais valorizados na organização, assim como pode contribuir para que seu desempenho possa ser aumentado ou reduzido, dependendo de como se sente em relação às práticas organizacionais. A definição de justiça organizacional está vinculada à maneira como as pessoas percebem as práticas das organizações, não estando atrelada às práticas exatamente (Ceribeli, Ferreira, \& Botelho, 2017).

Em outra perspectiva, Terzi, Dülker, Altn, Çelik, Dalkran, Yulcu, Tekin e Deniz (2017) consideram que a justiça organizacional e a identificação no trabalho são elementos que influenciam as condutas e os comportamentos dos trabalhadores no ambiente de trabalho. A justiça organizacional representa a psicologia da justiça concentrada no contexto organizacional, que tem como foco as percepções de justiça existentes entre as relações dos trabalhadores e suas empresas (Assmar, Ferreira, \& Souto, 2005). Conhecer os efeitos positivos ou negativos decorrentes da percepção de justiça ou injustiça organizacional é importante para o processo de identificação das crenças, dos sentimentos e das expectativas dos funcionários, reforçando mecanismos e práticas gerenciais agentes de justiça e evitando no caso de injustiça (Assmar et al., 2005).

A justiça organizacional é um tema que demanda uma grande importância para os estudos de diferentes áreas, como sociologia, psicologia social e psicologia organizacional, além de ser um assunto primordial relacionado com as análises no âmbito político, social e econômico (Mendonça, 2003). As percepções de justiça são importantes tanto para o andamento eficaz das empresas como para o bem-estar dos indivíduos que nela trabalham (Poole, 2007).

Assim sendo, o comportamento organizacional positivo propõe a melhora no desempenho individual e organizacional no contexto da instituição, não representando apenas a promoção da função organizacional (Pan, Chen, $\mathrm{Hao}, \& \mathrm{Bi}, 2018)$. As ações e os comportamentos positivos no trabalho estão relacionados com níveis mais altos de percepções de justiça. Assim, a justiça organizacional é definida por ser "a justiça percebida pelos empregados no que se refere às relações de trabalho intraorganizacional” (Klein, 2017, p. 87).

Mendonça e Mendes (2005) complementam que a injustiça organizacional provoca sofrimento, o qual influencia a natureza e as características de retaliação, que podem auxiliar o indivíduo a se proteger desse sofrimento. Os autores consideram que a manutenção de ambientes injustos pode trazer potenciais ameaças de desavenças, atitudes negativas e ações contrárias ao desempenho eficaz das organizações e de seus funcionários. Quando os funcionários não percebem ações justas, surgem sentimentos negativos em relação ao contexto laboral, tais como abatimento, estresse, esgotamento e falta de entusiasmo em trabalhar (Gomes, Estivalete, \& Ramadam, 2020).

Desse modo, a percepção de justiça dos colaboradores impacta no seu modo de visualizar as relações entre os colegas de trabalho e os gestores, ao considerar as iniciativas e ações existentes, e nas tomadas de decisão, podendo gerar a sensação de injustiça, contribuindo para o adoecimento do colaborador. Os bancários têm sido objeto de estudo de diversas pesquisas relacionadas à saúde do trabalhador (Lipp, 1996; Andrade, 2001), pois os problemas podem trazer ao indivíduo a percepção de injustiça frente à organização, assim como desencadear processos de intenso estresse.

Segundo Aslam e Sadaqat (2011), se os trabalhadores são tratados de forma justa na organização, sentem a necessidade de retribuir por meio de comportamentos positivos. Tais elementos elucidam a importância de compreender a justiça organizacional no ambiente de trabalho. Partindo dessas considerações, delimitou-se o seguinte problema de pesquisa: qual é a percepção de justiça organizacional dos colaboradores que atuam em bancos públicos e privados de uma cidade do interior do estado do Rio Grande do Sul, no Brasil?

Para responder tal questionamento o objetivo deste trabalho é analisar a percepção de justiça organizacional dos colaboradores que atuam em bancos públicos e privados de uma cidade do interior do estado do Rio Grande do Sul, no Brasil. Na intenção de atingir o objetivo geral, delimitou-se como objetivos específicos: i) identificar a percepção de justiça distributiva, processual e interacional em bancos públicos; ii) verificar a percepção de justiça distributiva, processual e interacional em bancos privados; iii) analisar a diferença de percepção de justiça organizacional entre os setores público e privado.

A contribuição deste estudo está em identificar realidades organizacionais do setor bancário, tanto público quanto privado, com o intuito de contribuir para a tomada de decisões e de ações frente aos colaboradores, tendo em vista a percepção que eles possuem em relação à justiça organizacional e seus possíveis comportamentos. Além disso, este estudo pode fornecer dados para que sejam realizadas comparações com outros ambientes laborais $e$ com um maior número de participantes. 


\section{REFERENCIAL TEÓRICO}

\subsection{Justiça organizacional}

A justiça organizacional tem uma história antiga no campo do estudo, a qual exerce um papel basilar em qualquer instituição (Sharma \& Yadav, 2017). Autores como Siqueira e Gomide Júnior (2004) afirmam que, em 1963, já se estudava o tema justiça organizacional, trazendo à luz a visão de Adams. De acordo com Adams (1963), os indivíduos pesam os investimentos e retornos nos relacionamentos sociais e a decisão de permanecer nessas relações depende do quanto de justiça é percebida pelos indivíduos. Por exemplo, se uma pessoa percebe que os seus investimentos foram proporcionais aos investimentos de outro indivíduo, ela permanece na organização, caso o indivíduo sinta-se injustiçado, ele desenvolve estratégias cognitivas de compensação que, ao falharem, levam a desistência da relação (Adams, 1963 como citado em Siqueira \& Gomide Júnior, 2004).

Jerald Greenberg foi outro pesquisador que, em meados do ano de 1987, estudou as concepções, percepções e reações relacionadas à justiça e à injustiça recebidas pelos funcionários em relação às organizações que trabalhavam, denominando de justiça organizacional (Assmar et al., 2005). Para Greenberg (1993), a justiça organizacional desempenha um importante papel para as relações e constitui requisito fundamental para o andamento eficaz das empresas e a satisfação dos seus membros.

Na visão de Rawls (2008), o justo e o injusto é sempre motivo de debate. A percepção de justiça varia de indivíduo para indivíduo, que entende a necessidade e coloca-se à disposição para confirmar um conjunto de princípios particulares para a atribuição de direitos e deveres básicos e para decidir a distribuição apropriada de benefícios e encargos da cooperação social. Esse raciocínio está conectado à justiça social, a qual Rawls (2008) considera uma forma de atribuir direitos e deveres em organizações básicas da sociedade, e determina a distribuição adequada dos benefícios e dos encargos da cooperação social.

Com base na ideia de imparcialidade e reciprocidade, Höffe (2003) discorre a respeito do conceito de justiça, o qual afirma que o objeto de justiça, o convívio, deve ser efetuado de forma que as suas vantagens e as suas desvantagens não sejam distribuídas entre grupos variados. Para se obter um resultado positivo, equilibrando as vantagens e as desvantagens, deve-se beneficiar cada pessoa e não ser conveniente com toda a sociedade enquanto coletividade. Para se criar um ambiente de segurança e justiça para os indivíduos é importante que se tenha padrões internos de equidade, a fim de estabelecer critérios de recompensa duradouros (Dutra, 2002).

A teoria da justiça organizacional foi desenvolvida a partir de pesquisas realizadas no contexto organizacional e se baseia na construção dos incidentes sociais de justiça e injustiça (Poole, 2007). Para esse autor, as percepções de justiça organizacional envolvem o contexto e, embora algumas normas possam ter influência nas percepções de justiça em determinadas situações, elas não decidem nem predizem como as pessoas (ou os grupos) irão visualizar ou responder às situações. Na visão de Assmar et al. (2005, p.444), "a justiça organizacional é a psicologia da justiça aplicada aos ambientes organizacionais, sendo focalizadas as percepções de justiça existentes nas relações entre trabalhadores e suas organizações". Para esses autores, Greenberg, a partir de seus estudos em 1987, considerou o termo justiça organizacional como "os estudos sobre as concepções, percepções e reações de (in) justiça por parte dos empregados em relação às organizações em que trabalham".

Klein (2017) possibilita o entendimento de que os incentivos financeiros, apesar de buscarem motivar os gestores a partir da combinação de compensação financeira ao desempenho, nem sempre conduzem ao alinhamento dos objetivos organizacionais com os pessoais. Atentar somente aos aspectos econômicos na elaboração de projetos de incentivo não basta. A literatura recomenda que questões comportamentais devem ser levadas em consideração nos contratos de incentivo aos empregados, em especial quanto à justiça (Klein, 2017).

Em outra perspectiva, Balven, Fenters, Siegel e Waldman (2018) afirmam que a justiça organizacional representa uma espécie final de microprocesso relacionado à interação entre questões pessoais e organizacionais, abarcando um processo cognitivo interno à pessoa. Tais autores complementam que essa cognição considera as situações ou as políticas vivenciadas na organização, sendo categorizada como um microprocesso que ocorre no ambiente organizacional. Percebe-se que a justiça organizacional representa a percepção de justiça dos membros da organização sobre a presença de justiça ou a sua ocorrência no ambiente organizacional (Sembiring, Nimran, Astuti, \& Utami, 2020).

A fim de sintetizar algumas definições de pesquisadores sobre a justiça, apresentamos o Quadro 1, com a definição basilar de justiça e as definições dos autores considerando o ambiente organizacional. 
Quadro 1 - Síntese das definições de justiça.

\begin{tabular}{|c|c|}
\hline \multicolumn{2}{|r|}{ Definição basilar de justiça } \\
\hline \multicolumn{2}{|c|}{$\begin{array}{l}\text { Os indivíduos pesam os investimentos e retornos nos relacionamentos sociais e a decisão de permanecer nessas relações } \\
\text { depende do quanto de justiça é percebida pelos indivíduos (Adams, 1963). }\end{array}$} \\
\hline AUTORES & DEFINIÇÕES DE JUSTIÇA ORGANIZACIONAL \\
\hline Höffe (2003) & $\begin{array}{l}\text { Implica em atitudes e comportamentos fundamentais para um bom desempenho e sem ele dificilmente são } \\
\text { alcançados os resultados esperados pelos funcionários. }\end{array}$ \\
\hline $\begin{array}{l}\text { Assmar et al. } \\
\quad(2005)\end{array}$ & $\begin{array}{l}\text { É a psicologia da justiça aplicada aos ambientes organizacionais, sendo focalizadas as percepções de } \\
\text { justiça existentes nas relações entre trabalhadores e suas organizações. }\end{array}$ \\
\hline Rawls (2008) & É a virtude principal das instituições sociais, bem como a verdade é nos sistemas de pensamento. \\
\hline Klein (2017) & Representa a justiça percebida pelos trabalhadores quanto às relações de trabalho intraorganizacional. \\
\hline $\begin{array}{l}\text { Balvin et al. } \\
\quad(2018)\end{array}$ & $\begin{array}{l}\text { É um tipo final de microprocesso relacionado à interação entre questões pessoais e organizacionais, } \\
\text { abarcando um processo cognitivo interno à pessoa. }\end{array}$ \\
\hline $\begin{array}{l}\text { Sembiring et } \\
\text { al. }(2020)\end{array}$ & $\begin{array}{c}\text { É a percepção de justiça dos integrantes da organização acerca da justiça que existe ou a sua ocorrência no } \\
\text { ambiente organizacional. }\end{array}$ \\
\hline
\end{tabular}

Fonte: Elaborado pelas autoras com base em Siqueira e Gomide Júnior (2004), Höffe (2003), Assmar et al. (2005), Rawls (2008), Klein (2017), Balvin et al. (2018) e Sembiring et al. (2020).

Na concepção de Siqueira e Gomide Júnior (2004), as pesquisas sobre as percepções de justiça em contextos organizacionais têm revelado que as percepções são fatores determinantes de vínculos do colaborador com a organização e que estes possuem diferentes naturezas. As pesquisas empíricas sobre a justiça organizacional demonstram que os trabalhadores fazem julgamentos com base em diversos fatores, como a "qualidade" de liderança, como seus líderes tratam seus funcionários e o relacionamento em longo prazo dos líderes com a organização (Poole, 2007).

Além disso, se os colaboradores percebem que há processos justos, o tratamento é com respeito, as decisões são justificadas e suas identidades são legitimadas, eles ficam com maior predisposição a aceitar resultados desfavoráveis. No entendimento de Pan et al. (2018), os colaboradores refletirão comportamentos positivos e maior produtividade se considerarem suas organizações como justas, tanto nos processos quanto nos sistemas de distribuição, contribuindo, assim, para o alcance de melhores resultados.

Singh e Singh (2018) consideram que a exposição de justiça e a geração de um ambiente de trabalho salutar são essenciais para os bancários de distintas categorias e importantes para a maximização da produtividade. Dessa forma, quando ocorre a percepção de justiça pelos trabalhadores no ambiente de trabalho e há capacitação, existe uma tendência de envolvimento nos comportamentos de ajuda que, consequentemente, interferem na satisfação no trabalho.

\subsection{As dimensões da justiça organizacional: distributiva, interacional e processual}

Alguns autores, como Mendonça (2003) e Al-Zu'bi (2010), consideram que as percepções dos trabalhadores estão relacionadas com três dimensões de justiça organizacional: justiça distributiva, justiça processual e justiça interacional. Dentre as pesquisas sobre a temática, destaca-se, neste estudo, a realizada por Mendonça et al. (2003), que construiu e validou um instrumento a fim de medir a percepção de justiça organizacional do trabalhador para uso no Brasil, denominado Escala de Percepção de Justiça Organizacional (EPJO), que constatou que a justiça organizacional é formada pelas dimensões citadas anteriormente.

A justiça distributiva identifica a percepção do trabalhador quanto ao recebimento de recompensas justas em relação aos investimentos gastos na organização. A justiça processual envolve o controle de voz (direito em emitir opinião), a representatividade (possuir representantes na tomada de decisões), o estabelecimento de critérios (decisões com base em critérios), o feedback (retorno ao funcionário em relação ao seu desempenho) e a coleta de informações (preocupação em ter conhecimento dos problemas da organização). A justiça interacional investiga o processo de interação dos gerentes para a condução dos procedimentos, tem foco nos relacionamentos interpessoais do gestor e do funcionário e no fornecimento de informações (Mendonça, 2003).

A reação do indivíduo no processo distributivo deve ser compreendida de acordo com a análise de todo o contexto em que ocorre a distribuição de recompensas (Almeida \& Silva, 2006). De acordo com Mendonça (2003), os termos injustiça distributiva e inequidade possuem uma correspondência entre si, bem como a justiça distributiva e equidade, contudo é preciso diferenciar esses termos. A literatura demonstra que a justiça distributiva foi a primeira que despertou o interesse de cientistas, como Adams, em 1965. Essa dimensão da justiça tem foco no conteúdo, que os fins alcançados ou obtidos sejam justos, como o salário, as avaliações de desempenho, entre outros fatores (Rego, 2002). A justiça distributiva focaliza a "justiça de recursos positivos ou negativos, entendidos como bens, serviços, promoções, salários, sanções disciplinares, entre outros" (Assmar et al., 2005, p.444). 
Em seu estudo, Andrade (2010) verificou a percepção de justiça distributiva no clima organizacional em organizações brasileiras diferenciadas pelo destaque na sua qualidade, partindo da premissa de que a dimensão justiça distributiva é considerada fator crítico para a qualidade da empresa. Os resultados da pesquisa demonstraram que a justiça distributiva representa um elemento fundamental para a avaliação do clima organizacional. No entanto, para Demo (2008), a dimensão distributiva não é suficiente para compreender toda a complexidade do tema justiça organizacional, visto que o fenômeno se caracteriza como multidimensional. Em virtude disso, demonstra-se a dimensão procedimental, processual ou de procedimentos da justiça (Demo, 2008).

Na visão de Al-Zu'bi (2010), a ênfase tem sido dada de forma gradual da justiça distributiva à justiça processual, pois se constata que os métodos utilizados para produzir os resultados podem ser mais importantes do que os próprios resultados. Na década de 70 iniciaram-se as pesquisas empíricas sobre a justiça processual nas organizações (Poole, 2007). Sob essa perspectiva, a justiça foi definida com relação aos procedimentos justos a partir das decisões, pois somente as decisões eram consideradas oriundas de processos justos. Estudiosos como Thibaut e Walker, segundo Rego (2002), afirmam que a justiça procedimental se refere ao processo, nos meios utilizados para alcançar os fins. A justiça procedimental surge de decisões juridicamente vinculantes, oriundas de procedimentos claros, e não tendo importância principal os conteúdos ou resultados, e sim as competências, os processos e as formalidades (Höffe, 2003).

Embora diversos estudiosos tenham separado a justiça processual e a interacional, as organizações devem visualizar a justiça em um amplo contexto social, demonstrando que tanto os procedimentos formais quanto os sociais da justiça organizacional são fundamentais na previsão dos resultados e na compreensão do comportamento organizacional (Coetzee, 2005). A justiça interpessoal refere-se às diversas ações que incluem a sensibilidade social e o tratamento com que os supervisores oferecem aos funcionários de forma respeitosa e digna (Al-Zu'bi, 2010). Do ponto de vista de Poole (2007), o termo justiça interacional refere-se aos contatos sociais, que foi, posteriormente, discutido como justiça relacional. A partir disso, essa perspectiva interacional diz respeito às decisões que eram justificadas e afetavam os colaboradores da organização.

Para os trabalhadores, a justiça era alcançada à medida que percebiam que os líderes buscavam justificar as suas decisões. Assmar et al. (2005) entendem que a justiça interacional compreende os aspectos sociais nas relações entre os indivíduos que tomam as decisões e os indivíduos que são afetados. Os líderes da organização representam o maior vínculo da empresa-colaborador e do representante da empresa junto ao colaborador, pois é a partir do líder que o indivíduo visualiza a organização e inclui os seus valores, metas e objetivos (Ribeiro, 2006). Assim, o indivíduo percebe a justiça praticada pela organização por meio de suas lideranças (Ribeiro, 2006).

Em estudos mais atuais, como o de Balven et al. (2018), os autores apresentam um modelo quadridimensional (justiça distributiva, processual, interpessoal e informacional). A justiça distributiva pode ser compreendida como os resultados e contribuições do indivíduo percebidos pela organização. A justiça processual refere-se à percepção do colaborador em relação a preconceitos na determinação dos resultados organizacionais (Balven et al., 2018). A justiça interpessoal faz referência aos relacionamentos formados entre indivíduo e organização. Por fim, a justiça informacional refere-se às informações fornecidas pela organização, devendo ser francas e individualizadas (Balven et al., 2018).

Destarte, esta pesquisa optou em utilizar o modelo tridimensional em virtude de ser o mais utilizado pelos pesquisadores, permitindo análise com confiança e segurança, relacionando as dimensões da justiça organizacional: distributiva, processual e interacional (Meireles, 2006).

\subsection{O setor bancário e seus colaboradores}

Para entender o setor bancário, considera-se pertinente recapitular alguns momentos da história. Inicialmente destaca-se a importância desse setor para a sociedade. O setor bancário representa um importante pilar do sistema econômico em todo o mundo, em virtude do seu impacto fundamental sobre o crescimento e o desenvolvimento estável, além de sua função de intermediário na movimentação de fundos (Mohamed, 2016). A compreensão da evolução do sistema financeiro do Brasil exige a análise dos períodos de transformação no âmbito político, social e econômico, que possibilitaram a atual configuração (Metzner \& Matias, 2015). Um dos destaques dessa modificação foi a elaboração da Lei n. ${ }^{\circ}$ 4.595, em 1964, que sistematiza sobre a política e as instituições bancárias, monetárias e creditícias, além de criar o Conselho Monetário Nacional (Brasil ,1964).

No contexto bancário brasileiro, Camargo (2009) considera que aconteceram mudanças essenciais na década de 90, tanto na estrutura quanto nas questões envolvendo a concorrência. O Brasil passou a adotar a abertura comercial e financeira, devido à tendência no contexto mundial de liberalização nos diversos mercados. A partir dessa reestruturação, os bancos dos outros países expandiram amplamente a sua participação no nosso país, intensificando as fusões e as aquisições, que passaram a elevar a concentração bancária (Camargo, 2009).

A partir disso, inúmeras incertezas passaram a surgir no sistema bancário brasileiro, exigindo maior produtividade e o aumento da qualificação dos colaboradores (Marques \& Giongo, 2016). Para esses autores, a proeminente reestruturação financeira nacional e internacional gerou insegurança nos profissionais em relação à estabilidade $e$ ao rompimento das relações de confiança. 
Os estudos de Marques e Giongo (2016) demonstraram que, entre as principais experiências de sofrimento dos trabalhadores bancários no Brasil - apresentadas em trabalhos publicados -, nos anos de 2005 a 2015, estão o incentivo a ações individualistas, o assédio moral, a sensação de perda de identidade, à medida que não pode demonstrar suas vontades, e os sentimentos de insegurança, decepção e ansiedade, além de receio e pressão psíquica.

Pelo fato de trabalharem nos ambientes de grande circulação de pessoas e de quantidades de valores, os bancários são potenciais vítimas de assalto, deixando-os vulneráveis a terem sofrimentos psicológicos devido a essa experiência (Schneider, 2011). Entretanto, ao analisar a justiça organizacional no cenário bancário, algumas situações referentes ao estresse e ao adoecimento físico e mental podem ser minimizadas (Gomes et al., 2020).

De acordo com Bhatla (2017), os profissionais bancários perseguem normas, políticas e regulamentos, com foco nos objetivos institucionais, executando seu trabalho de modo consciente e corretamente. Eles exibem, com isso, mais comportamentos de cidadania organizacional. Desse modo, Mohamed (2016) ressalta a relevância da governança corporativa nesse processo, com a aplicação de boas práticas gerenciais, a fim de assegurar a justiça financeira e definir um modelo para a preservação dos direitos dos stakeholders.

\section{METODOLOGIA}

A metodologia de pesquisa adotada para a realização deste estudo foi quantitativa, do tipo survey, com enfoque descritivo. A pesquisa survey pode ser considerada conforme o número de momentos no tempo no qual há a coleta de dados: longitudinal, acontece em períodos ou pontos específicos, buscando analisar a evolução ou mudanças, e cross-sectional (corte transversal), que ocorre em um determinado momento, a fim de descrever e analisar o estado de uma ou diversas variáveis e não permite uma análise através do tempo (Sampieri, Collado, \& Lucio, 1991).

O presente estudo foi caracterizado como survey cross-sectional, pois se buscou examinar a percepção dos colaboradores do setor bancário público e privado quanto à justiça organizacional em certo momento, não podendo ser comparado com outros períodos de tempo. Os colaboradores do setor bancário (público e privado) de uma cidade do interior do estado do Rio Grande do Sul, no Brasil, foram o foco da pesquisa. Grande parte dos colaboradores encontra-se em bancos públicos (513), pertencentes a 18 agências, portanto a minoria está em bancos privados (162), correspondente a 9 agências. $O$ total de colaboradores bancários nessa cidade, no momento de realização da pesquisa, era de 675 .

Foram excluídas do presente estudo as cooperativas de crédito e financeiras dessa cidade, os postos de atendimento bancário (PAB), as áreas departamentais e superintendências dessas instituições. Foram incluídos os colaboradores das agências bancárias, públicas e privadas, visto que, segundo Grisci e Bessi (2004), essa população se caracteriza pelo atendimento ao público e à venda de produtos. Desse modo, participaram do estudo 224 colaboradores do setor bancário público $(66,08 \%$ do total de respondentes) e 115 do privado $(33,92 \%)$, compreendendo $50,22 \%$ de respostas em relação ao total.

Os colaboradores foram informados de que não seriam identificados na pesquisa, tampouco os bancos e agências dos quais fazem parte. Além disso, adotou-se como técnica de coleta de dados um questionário estruturado, com o objetivo de analisar a percepção de justiça organizacional segundo os colaboradores que atuam em bancos públicos e privados, por meio da EPJO de Mendonça et al. (2003). Esse instrumento foi validado para o contexto brasileiro, corroborando a estrutura de justiça como um constructo que se revela por meio de três dimensões: justiça distributiva, processual e interacional (Mendonça et al., 2003).

A análise da EPJO ocorreu por meio de uma perspectiva tridimensional, com a medição das dimensões processual, interacional e distributiva por meio de testes estatísticos descritivos (frequências, médias, medianas e desvio padrão), indicador de consistência interna alfa de Cronbach e testes de normalidade. A escala adotada é do tipo Likert, com opções de respostas do "discordo totalmente" (1) ao "concordo totalmente" (5). As respostas foram classificadas como "alta justiça" quando apresentaram valores acima de 3,0 (média da escala Likert) e "baixa justiça" quando abaixo de 3,0 .

\section{RESULTADOS QUANTO À PERCEPÇÃO DE JUSTIÇA ORGANIZACIONAL}

Quanto aos resultados obtidos na pesquisa, pode-se verificar que os valores do coeficiente alfa de Cronbach para a EPJO foram: justiça distributiva $(\alpha=0,926)$, justiça processual $(\alpha=0,871)$ e justiça interacional $(\alpha=0,918)$. Todas as dimensões da justiça organizacional tiveram valores considerados satisfatórios para a análise da confiabilidade, pois apresentaram alfa de Cronbach maior que 0,7 (Hair, Babin, Money, \& Samouel, 2005).

O desvio padrão das três dimensões foi considerado uniforme, pois revelou valores abaixo de 1,0 (justiça distributiva 0,94 , justiça processual 0,81 e justiça interacional 0,89 ). De modo geral, as dimensões de justiça organizacional tiveram médias e medianas iguais ou superiores a três. A maior parte dos pesquisados considera justas as ações das organizações. O Quadro 2 apresenta as médias, medianas, classificações, percentuais e frequências das dimensões da EPJO de modo geral, as quais serão analisadas na seção de discussão dos resultados. 
Quadro 2 - Mediana, média, desvio padrão, classificação, percentual e frequência das dimensões da EPJO, de modo geral.

\begin{tabular}{|c|c|c|c|c|c|c|}
\hline Dimensões da EPJO & Mediana & Média $(\mu)$ & DesvioPadrão & Classificação & Percentual (\%) & Frequência (n) \\
\hline \multirow{3}{*}{ Distributiva } & \multirow{3}{*}{3,00} & \multirow{3}{*}{3,02} & 0,94 & Alta & $46,61 \%$ & 158 \\
\hline & & & & Baixa & $53,39 \%$ & 181 \\
\hline & & & & Total & $100,00 \%$ & 339 \\
\hline \multirow{3}{*}{ Processual } & \multirow{3}{*}{3,14} & \multirow{3}{*}{3,17} & 0,81 & Alta & $47,79 \%$ & 162 \\
\hline & & & & Baixa & $52,21 \%$ & 177 \\
\hline & & & & Total & $100,00 \%$ & 339 \\
\hline \multirow{3}{*}{ Interacional } & \multirow{3}{*}{3,57} & \multirow{3}{*}{3,51} & 0,89 & Alta & $54,28 \%$ & 184 \\
\hline & & & & Baixa & $45,72 \%$ & 155 \\
\hline & & & & Total & $100,00 \%$ & 339 \\
\hline
\end{tabular}

Fonte: Elaborado pelas autoras, com base nos dados da pesquisa.

Os resultados também foram analisados de acordo com o setor, público ou privado, a fim de comparar as percepções dos colaboradores. Logo, constatou-se que, os pesquisados do setor público consideram mais justas as ações, com médias superiores a três. A dimensão de justiça organizacional que recebeu maior média foi a interacional. Ao verificar a percepção de justiça organizacional dos colaboradores de bancos públicos e privados por meio do cálculo do teste Qui-Quadrado, verificou-se que as diferenças entre as três dimensões foram significativas estatisticamente $(p=<0,0001)$, conforme apresenta o Quadro 3.

Quadro 3 - Classificações, percentuais e frequências das dimensões da EPJO, em bancos públicos e privados.

\begin{tabular}{|c|c|c|c|c|c|c|c|c|c|}
\hline \multirow{2}{*}{ EPJO } & \multicolumn{4}{|c|}{ Bancos públicos (média geral $=3,00$ ) } & \multirow[b]{2}{*}{$\boldsymbol{\mu}$} & \multicolumn{3}{|c|}{ Bancos privados (média geral= 3,67 ) } & \multirow{2}{*}{$\begin{array}{l}\text { Teste Qui- } \\
\text { Quadrado }\end{array}$} \\
\hline & $\mu$ & Classif & $\%$ & Freq. & & Classif & $\%$ & Freq & \\
\hline \multirow{3}{*}{ Distributiva } & \multirow{3}{*}{2,77} & Alta & $36,16 \%$ & 81 & \multirow{3}{*}{3,49} & Alta & $66,96 \%$ & 77 & \multirow{3}{*}{$<0,0001$} \\
\hline & & Baixa & $63,84 \%$ & 143 & & Baixa & $33,04 \%$ & 38 & \\
\hline & & Total & $100,00 \%$ & 224 & & Total & $100,00 \%$ & 115 & \\
\hline & & & & & & & & & \\
\hline \multirow{3}{*}{ Processual } & \multirow{3}{*}{2,96} & Alta & $37,95 \%$ & 85 & \multirow{3}{*}{3,56} & Alta & $66,96 \%$ & 77 & \multirow{4}{*}{$<0,0001$} \\
\hline & & Baixa & $62,05 \%$ & 139 & & Baixa & $33,04 \%$ & 38 & \\
\hline & & Total & $100,00 \%$ & 224 & & Total & $100,00 \%$ & 115 & \\
\hline & & & & & & & & & \\
\hline \multirow{3}{*}{ Interacional } & \multirow{3}{*}{3,28} & Alta & $45,54 \%$ & 102 & \multirow{3}{*}{3,95} & Alta & $71,30 \%$ & 82 & \multirow{3}{*}{$<0,0001$} \\
\hline & & Baixa & $54,46 \%$ & 122 & & Baixa & $28,70 \%$ & 33 & \\
\hline & & Total & $100,00 \%$ & 224 & & Total & $100,00 \%$ & 115 & \\
\hline
\end{tabular}

Fonte: Elaborado pelas autoras, com base nos dados da pesquisa.

\section{DISCUSSÃO}

Ao analisar a média geral sobre a percepção de justiça organizacional $(\mu=3,23)$, pode-se verificar que, embora o valor tenha sido pouco acima da média $(\mu=3,00)$, representa que há sentimento de justiça organizacional em boa parte das práticas existentes nas organizações. Nesse sentido, destaca-se o comentário de Ceribeli et al. (2017), em que há relação positiva entre a percepção de justiça no trabalho e as oportunidades de crescimento profissional entre os colaboradores. Como a presente pesquisa foi realizada no setor bancário, a possibilidade de receber oportunidades de elevação na carreira, vislumbradas no ambiente de trabalho, pode ter influenciado as percepções dos pesquisados. Todavia os autores Ceribeli et al. (2017) também identificaram em seus estudos que não houve relação entre a justiça laboral e os colaboradores terem pretensão de permanecer no trabalho.

Outra pesquisa relevante no campo da justiça organizacional foi realizada por Lipponen, Steffens e Holtz (2017), visando compreender a formação da percepção de justiça e o apoio em situações de lay-off (suspensão temporária do trabalho). Os autores identificaram que a ideia de justiça organizacional e de apoio podem ser desenvolvidas por meio de gestores considerados justos, particularmente quando há uma identidade de grupo de trabalho compartilhada entre os gestores e as vítimas de lay-off (Lipponen et al., 2017). 
Em relação às dimensões de justiça organizacional, constatou-se que os colaboradores entendem que há mais justiça interacional em suas organizações, correspondendo a maior média $(\mu=3,51)$ entre as dimensões, com $54,28 \%$ dos pesquisados $(n=184)$ e desvio padrão de 0,89 , denotando que houve pouca variabilidade nas respostas. Para Al-Zu'Bi (2010), essa dimensão está relacionada às atividades que abrangem a sensibilidade social e o tratamento recebido por suas chefias, de forma respeitosa e digna.

$\mathrm{Na}$ linha de entendimento de Filenga e Siqueira (2006), a justiça organizacional está relacionada às bases do comprometimento organizacional (afetiva, calculativa e normativa). Os resultados da pesquisa dos autores apresentaram que parte do comprometimento afetivo do colaborador foi explicada pela justiça de procedimentos, enquanto que uma parcela do comprometimento normativo e do calculativo explicaram a justiça distributiva. A partir disso, os autores confirmaram a necessidade de investir em justiça organizacional nas empresas que desejam elevar os níveis de comprometimento de seus colaboradores.

Além da justiça interacional, outra dimensão que se destacou foi a processual, com a média de 3,17 (desvio padrão de 0,81 ), demonstrando que os dados não foram muito afastados da média. Contudo os colaboradores perceberam como baixa a justiça processual e a distributiva, representadas por $52,21 \%$ e $53,39 \%$, respectivamente. Tais dados demonstram que os colaboradores consideram que recebem, em parte, procedimentos justos na distribuição de trabalho. Ressalta-se, ainda, que a justiça distributiva foi a menos percebida pelos colaboradores, com a menor média de 3,02 e desvio padrão de 0,94, apresentando certa variabilidade nas respostas.

Sharma e Yadav (2017), em seus estudos, identificaram que a justiça organizacional possui uma importante relação positiva sobre o envolvimento dos colaboradores no trabalho. Em perspectiva semelhante, Filenga e Siqueira (2006) compartilham o entendimento de que a percepção de justiça produz impacto no comprometimento organizacional, sobretudo no que se refere à justiça distributiva e a de procedimentos. Além disso, para Mendonça e Mendes (2005), a percepção de injustiça pode causar sofrimento ao sujeito. Essa situação pode esclarecer as atitudes retaliatórias no ambiente organizacional, que tem o propósito de gerar uma proteção ao trabalhador devido ao mal-estar vivenciado (Mendonça \& Mendes, 2005). Na concepção de Pan et al. (2018), a justiça processual é a mais propícia a suscitar dos funcionários comportamentos organizacionais positivos, ao passo que a injustiça distributiva tende a ocasionar comportamentos organizacionais negativos.

Ao realizar a comparação entre a percepção de justiça organizacional em bancos públicos e privados, percebeuse que os colaboradores do setor privado consideram que há mais justiça organizacional que os do setor público. Esses dados tornam-se relevantes no sentido de que, para Fiuza (2010), a percepção de justiça organizacional é grande preditora da percepção de políticas de gestão de pessoas - demonstrando que os colaboradores de instituições privadas concebem da melhor forma as práticas organizacionais, especialmente referentes aos recursos humanos assim como na visão de Terzi et al. (2017), os quais identificaram que a justiça organizacional prognóstica as atitudes de identificação organizacional.

Em relação às dimensões da EPJO, constatou-se que a dimensão justiça interacional foi a que obteve maior valor, correspondendo às médias de 3,28 nas instituições públicas e 3,95 em privadas, evidenciando que há, por parte dos colaboradores, percepção significativa em relação a essa variável. A dimensão justiça interacional referese à superação dos gestores em relação aos favorecimentos pessoais no trabalho, na preocupação dos gestores com os direitos dos colaboradores e em considerar as suas opiniões. Essa dimensão engloba ainda aspectos como a sinceridade e a franqueza dos gestores, o fornecimento de informações sobre a forma como o trabalhador está desempenhando suas atividades, permitindo que ele faça o melhor no seu trabalho. Inclui-se também na percepção de justiça interacional o ato do gestor fornecer justificativas a respeito das decisões relacionadas ao trabalho dos colaboradores (Mendonça, 2003).

Os vínculos que apresentam natureza mais egoística levam em consideração as satisfações mais exatas e estão vinculados à percepção de justiça de distribuição. No entanto os vínculos mais altruísticos, geralmente baseados em valores mais sociais, relacionam-se à percepção de justiça dos procedimentos (Siqueira \& Gomide Júnior, 2004). Destaca-se que a média da justiça interacional no setor privado foi maior, o que pode estar relacionado às particularidades do serviço público. Botelho e Paiva (2011) comentam a respeito das diferenças que há entre os setores, pois o serviço público está subordinado ao coletivo, em que prevalece o interesse da maioria ao individual. Além disso, Fiuza (2010) destaca que os indivíduos que prezam o prestígio social e a autoridade preferem ações que fortaleçam o status quo, como receber tratamento digno e respeito e obter informações relevantes a respeito da organização. As pessoas que se preocupam com a integração e o bem-estar de todos tendem a valorizar as ações de envolvimento, como a igualdade na participação e a realização de eventos integrativos (Fiuza, 2010).

Em relação à dimensão justiça processual, verificou-se valores pouco acima da distributiva, com a média de 2,96 (público) e 3,56 (privado). Ressalta-se que todas as médias das afirmações referentes à percepção de justiça organizacional foram maiores em bancos privados do que em públicos. Os colaboradores do setor bancário público percebem que há baixa justiça processual no contexto de trabalho; enquanto que, no setor privado, prevaleceu o inverso. Pode-se observar ainda que, no setor bancário público, a maioria das respostas para as três dimensões apresentaram baixa percepção de justiça organizacional (justiça distributiva: $63,84 \%, \mu=2,77, n=143$; justiça processual: $62,05 \%, \mu=2,96, n=139$; interacional: $54,46 \%, \mu=3,28, n=122$ ). Já no setor bancário privado, predominou a alta 
percepção de justiça entre os pesquisados para as três dimensões (justiça distributiva: $66,96 \%, \mu=3,49, n=77$; justiça processual: $66,96 \%, \mu=3,56, n=77$; justiça interacional: $71,30 \%, \mu=3,95, n=82$ ).

Esses resultados permitem compreender a importância que deve ser dada pelos gestores às percepções de justiça dos colaboradores, assim como à forma com que os trabalhadores se comportam quando percebem que recebem tratamento injusto, visto que tais ações podem prejudicar a efetividade organizacional (Mendonça, 2003).

\section{CONCLUSÃO}

É importante ressaltar que as pesquisas acerca da justiça são fundamentais para a análise de assuntos relacionados às questões sociais, econômicas e políticas da sociedade organizada. Tornam-se, portanto, um construto com status próprio no âmbito da psicologia social e organizacional (Mendonça, 2003), assim como na administração de empresas. Mendonça e Mendes (2005) destacam que o sentimento de injustiça no trabalho faz com que o colaborador enfrente situações que irritam, desgastam, intimidam e desestimulam. Além disso, Grisci, Scalco e Kruter (2011) afirmam que os casos de bancários que apresentam saúde fragilizada não são raros, estando ligados à redução do tempo e ao aumento das pressões no trabalho.

O objetivo desta pesquisa foi analisar a percepção de justiça organizacional segundo os colaboradores que atuam em bancos públicos e privados de uma cidade do interior do estado do Rio Grande do Sul. Dessa forma, foi utilizada a Escala de Percepção de Justiça Organizacional, de Mendonça et al. (2003). Participaram deste estudo 339 colaboradores, sendo que 115 pertencem aos bancos privados $(33,92 \%)$ e 224 aos bancos públicos $(66,08 \%)$. Em relação à percepção de justiça, pode-se verificar que, de modo geral, os colaboradores percebem que há justiça organizacional $(\mu=3,23)$, representada pelas dimensões distributiva $(\mu=3,02)$, processual $(\mu=3,17)$ e interacional $(\mu=3,51)$, nas organizações em que trabalham.

As diferenças entre os setores público e privado nas três dimensões de justiça, no entanto, foram estatisticamente significativas. Os colaboradores pesquisados de bancos privados consideram que há mais justiça organizacional $(\mu=3,67)$ do que em bancos públicos $(\mu=3,00)$, pois os primeiros obtiveram maiores médias em todas as afirmações das dimensões de justiça (distributiva, processual e interacional). Ressalta-se também, entre as três dimensões de justiça, que os colaboradores percebem mais justiça interacional, tanto em bancos públicos $(\mu=3,28)$ quanto em privados $(\mu=3,95)$. Essa dimensão refere-se, entre vários fatores, aos favorecimentos pessoais dos gestores no trabalho, à preocupação com os direitos dos colaboradores e à consideração das opiniões (Mendonça, 2003).

Percebe-se que os relacionamentos no ambiente de trabalho se tornam fundamentais para as percepções de justiça dos colaboradores. O trabalho representa uma medida importante de integração social, tanto pela questão de subsistência quanto simbólica, fundamental para a formação dos indivíduos (Reis, Fernandes, \& Gomes 2010). Contudo, se os colaboradores percebem que o tratamento recebido pelos gestores e colegas é injusto, pode haver sofrimento no trabalho (Meireles, 2006). De modo geral, pode-se verificar que a percepção de justiça entre as relações de trabalho dos colaboradores pesquisados aparentemente não é causa de sofrimento psíquico no ambiente organizacional.

Devido a essa realidade, é necessário que os gestores tenham conhecimento continuamente dos sentimentos dos colaboradores, a fim de que a justiça empregada na organização contribua para a redução de estresse no trabalho, de adoecimento psicológico e, consequentemente, de adoecimento físico de seus colaboradores. Tal situação pode repercutir em afastamentos de colaboradores do local de trabalho e apatia devido à falta de desafios nas situações vivenciadas, causando excesso de gastos com pessoal e baixa produtividade.

Convém ressaltar, também, que a dimensão justiça distributiva foi a que recebeu menor valor nos dois setores, com a média de 2,77 (público) e 3,49 (privado). Nota-se que os colaboradores do setor bancário público, de modo geral, sentem-se pouco recompensados, de maneira justa, pelas atribuições em seu trabalho, esforços despendidos, experiência e qualidade do trabalho que apresentam, além do estresse a que são submetidos. Acrescenta-se ainda, nessa dimensão, a percepção do indivíduo em ser recompensado de forma justa pelo recebimento de um salário justo (Mendonça, 2003).

Além disso, destaca-se que, no setor privado, a média para a dimensão justiça distributiva foi mais elevada, demonstrando que os colaboradores percebem a existência dessa dimensão nas organizações pesquisadas, representando, para esse setor, maior clareza nos métodos organizacionais. A falta de transparência em relação às ações, quando ocorrem desigualdades, representa uma fonte de frustração da teoria da equidade na explicação sobre a justiça organizacional (Coetzee, 2005).

De acordo com Mendonça (2003), a dimensão justiça processual está relacionada com a possibilidade do colaborador em recorrer das decisões tomadas, aos critérios justos em relação a essas decisões e se há busca de informações antes dela ocorrer. Além disso, a justiça processual implica na participação de representantes dos colaboradores no processo de tomada de decisão quando há questões que possam influenciá-los diretamente, como a política salarial. Outro fator que repercute na percepção de justiça processual é se os colaboradores recebem feedbacks quanto às decisões acerca do seu trabalho e podem buscar esclarecimentos ou informações sobre as decisões tomadas pelos gestores.

Assim, com base no que foi explanado, pode-se perceber que existem diferenças significativas entre a percepção de colaboradores do setor bancário público e do privado quanto às dimensões da justiça organizacional (distributiva, 
processual e interacional). Partindo do pressuposto de que a injustiça inserida no contexto de trabalho causa sofrimento e repercute em variadas reações (Mendonça \& Mendes, 2005), é extremamente relevante que os gestores tomem conhecimento do que os colaboradores percebem em relação às ações organizacionais, para que as decisões sejam tomadas de forma eficiente. Diante dos resultados apresentados, constata-se que o objetivo deste estudo foi alcançado, pois foi identificada a percepção de justiça dos colaboradores que atuam em instituições bancárias do setor público e privado de uma cidade do interior do estado do Rio Grande do Sul.

Percebe-se que a pesquisa trouxe contribuições teóricas e empíricas para o futuro das organizações, relacionadas aos resultados obtidos no contexto bancário, podendo ser comparadas com outros estudos, evidenciando a importância da percepção de justiça nesse ambiente de alta pressão e insegurança. A pesquisa trouxe contribuições práticas para as organizações, visto que as percepções dos colaboradores diante de situações de justiça ou de injustiça podem influenciar e levar a um elevado desgaste na organização, ocasionando doenças psíquicas e emocionais, sendo necessária a adoção de práticas e políticas gerenciais justas e democráticas, que reduzam os sentimentos negativos acerca das organizações. Assim, a melhoria na percepção de justiça pode suscitar efeitos fenomenais nos comportamentos, nos desempenhos e nas decisões dos colaboradores e, de modo abrangente, das organizações em que atuam.

Destaca-se como principal limitação deste estudo, ao considerar as outras pesquisas já realizadas e outras escalas validadas sobre a justiça organizacional, que a discussão deu-se apenas sob a análise de um instrumento de medida, a EPJO, com abordagem tridimensional. Outrossim, a pesquisa foi realizada em uma cidade somente, podendo ser expandida em diferentes culturas, como em diferentes estados e países.

Sugere-se, para trabalhos futuros, a ampliação da pesquisa por meio de análise qualitativa e de entrevistas em profundidade com gestores e colaboradores, a fim de corroborar ou refutar os resultados obtidos. Convém, ainda, que sejam realizadas novas investigações da percepção de justiça organizacional com outras temáticas, como práticas de gestão de pessoas, conflitos interpessoais, comprometimento organizacional, comportamentos de cidadania organizacional, bem-estar, engajamento e estresse no trabalho.

\section{REFERÊNCIAS}

ALMEIDA, G. O.; SILVA, A. M. M. Justiça organizacional, impactos no burnout e o comprometimento dos trabalhadores. Revista Eletrônica de Gestão Organizacional, [S. I.], v. 4, n. 2, p. 160-175, 2006. Link. Acesso em: 20 ago. 2019.

Al-Zu'bi, H. A. A study of relationship between organizational justice and job satisfaction. International Journal of Business and Management, [S. I.] v. 5, n. 12, p. 102-109, 2010. DOI: 10.5539/ijbm.v5n12p102

ANDRADE, A. Ocorrência e controle subjetivo do stress na percepção de bancários ativos e sedentários; a importância do sujeito na relação "atividade física e saúde". 2001. Tese (Doutorado em Engenharia de Produção) - Universidade Federal de Santa Catarina, Florianópolis, 2001.

ANDRADE, S. M. Percepção de justiça distributiva no clima organizacional - um estudo sobre organizações brasileiras que buscam se destacar pela qualidade do ambiente de trabalho. 2010. Dissertação (Mestrado em Administração) - Faculdade de Economia, Administração e Contabilidade, Universidade de São Paulo, São Paulo, 2010.

ASLAM, R.; SADAQAT, S. Investigating the relationship of organizational justice on organizational citizenship behavior among teaching staff of university of the punjab, European Journal of Scientific Research, [S. I.], v. 57, n. 1, p. 53-67, 2011.

ASSMAR, E. M. L.; FERREIRA, M. C.; SOUTO, S. O. Justiça organizacional: uma revisão crítica da literatura. Psicologia: Reflexão e Crítica. [S. I.], v. 18, n. 3, p. 443-453, 2005.

BALVEN, R.; FENTERS, V.; SIEGEL, D. S.; WALDMAN, D. Academic entrepreneurship: the roles of identity, motivation, championing, education, work-life balance, and organizational justice. Academy of Management Perspectives, [S. I.], v. 32, n. 1, p. 21-42, 2018.

BHATLA, N. The effect of dimensions of the organizational citizenship behavior on performance of employees in finance sector with special reference to banking sector in lucknow. Asian Journal of Multidisciplinary Studies. [S. I.], v. 5, n. 4, 2017.

BOTELHO, R. D.; PAIVA, K. C. M. Comprometimento organizacional: um estudo no Tribunal de Justiça do Estado de Minas Gerais. Revista de Administração Pública - RAP, Rio de Janeiro, v. 45, n. 5, p. 249-283, set/out. 2011.

BRASIL. Lei n. 4.595, de 31 de dezembro de 1964. Dispõe sobre a política e as instituições monetárias, bancárias 
e creditícias, cria o Conselho Monetário Nacional e dá outras providências. Brasília, DF: Presidência da República, 1964. Link. Acesso em: 01 jun. 2019.

CAMARGO, P. O. A evolução recente do setor bancário no Brasil. São Paulo: Ed. UNESP, 2009.

CERIBELI, H. B.; FERREIRA, F. J. R.; BOTELHO, A. A. Análise da relação entre oportunidades de crescimento profissional, percepção de justiça dos funcionários e intenção de permanência na organização. Revista Globalización, Competitividad y Governabilidad, [S. I.], v. 11, n. 3, p. 111-130, 2017.

COETZEE, M. The fairness of affirmative action: an organisational justice perspective. 2005. Tese (Doutorado em Gestão de Recursos Humanos) - Faculty of Economic and Management Sciences, University of Pretoria, Pretoria, 2005.

DEMO, G. Políticas de gestão de pessoas nas organizações: papel dos valores pessoais e da justiça organizacional. 2. ed. São Paulo: Atlas. 2008.

DUTRA, J. S. Gestão de pessoas: modelo, processos, tendências e perspectivas. São Paulo: Atlas, 2002.

FILENGA, D.; SIQUEIRA, M. M. M. O impacto de percepções de justiça em três bases de comprometimento organizacional. Revista de Administração, [S. I.], v. 41, n. 4, p. 431-441, 2006.

FIUZA, G. D. Políticas de gestão de pessoas, valores pessoais e justiça organizacional. Revista de Administração Mackenzie, São Paulo, v. 11, n. 5, p. 55-81, set./out. 2010.

GOMES, T. C.; ESTIVALETE, V. F. B.; RAMADAM, A. O. Justiça organizacional e o estresse no trabalho de bancários. Revista Psicologia: Organizações e Trabalho, [S. I.] v. 20, n. 2, p. 994-1000, 2020.

GREENBERG, J. Stealing in the name of justice: informational and interpersonal moderators of theft reactions to underpayment inequity. Organizational Behavior and Human Decision Processes, [S. I.], v. 54, p. 81-103, 1993.

GRISCI, C. L. I.; BESSI, V. G. Modos de trabalhar e de ser na reestruturação bancária. Sociologias, v. 6, n. 12, p. 160-200, 2004.

GRISCI, C. L. I.; SCALCO, P. D.; KRUTER, G. E. Dilemas pessoais no trabalho imaterial bancário. Psicologia \& Sociedade, [S. I.], v. 23, n. 3, p. 564-573, 2011.

HAIR, J.; BABIN, B.; MONEY, A.; SAMOUEL, P. Fundamentos de métodos de pesquisa em administração. Porto Alegre: Bookman, 2005.

HÖFFE, O. O que é justiça? Tradução Peter Naumann. Porto Alegre: EDIPUCRS, 2003.

KLEIN, L. A percepção de justiça organizacional em contratos de incentivos e seu efeito na congruência entre objetivos pessoais e organizacionais. 2017. Tese (Doutorado em Contabilidade e Finanças) - Universidade Federal do Paraná, Curitiba, 2017.

LIPP, M. E. N (org.) Pesquisas sobre stress no Brasil: saúde, ocupações e grupos de risco. 2. ed. São Paulo: Papirus, 1996.

LIPPONEN, J.; STEFFENS, N.K.; HOLTZ, B. C. Prototypical supervisors shape lay-off victims' experiences of top management justice and organizational support. Journal of Occupational and Organizational Psychology, [S. I.], v. 91, n. 1, p. 158-180, Mar. 2017. DOI: 10.1111/joop.12197

MARQUES, G. S.; GIONGO, C. R. Trabalhadores bancários em sofrimento: uma análise da literatura nacional. Revista Psicologia: Organizações e Trabalho, [S. I.], v. 16, n. 3, p. 220-235, 2016. DOI: 10.17652/rpot/2016.3.704

MEIRELES, I. A. C. O impacto das percepções de justiça organizacional sobre as vivências de prazer e sofrimento no trabalho. Dissertação (Mestrado em Psicologia) - Universidade Católica de Goiás, Goiânia, 2006.

MENDONÇA, H. Retaliação organizacional: o impacto dos valores e da justiça. 2003. Tese (Doutorado em Psicologia) - Universidade de Brasília, Brasília, 2003. 
MENDONÇA, H.; MENDES, A. M. Experiências de injustiça, sofrimento e retaliação no contexto de uma organização pública do estado de Goiás. Psicologia em Estudo, [S. I.], v.10, n. 3, p. 489-498, 2005.

MENDONÇA, H.; PEREIRA, C.; TAMAYO, A.; PAZ, M. G. T. Validação fatorial de uma escala de percepção de justiça organizacional. Estudos: Saúde e Vida, [S. I.], v. 30, n. 1, p. 111-130, 2003.

METZNER, T. D.; MATIAS, A. B. O setor bancário brasileiro de 1990 a 2010. São Paulo: Manole, 2015. Link. Acesso em: 01 jun. 2019.

MOHAMED, W. M. W. Corporate governance practices of the middle east banking sector: a comparative analysis between islamic and conventional banks. Journal of Finance and Bank Management, [S. I.], v. 4, n. 1, p. 99-111, 2016.

PAN, X.; CHEN, M.; HAO, Z.; BI, W. The effects of organizational justice on positive organizational behavior: evidence from a large-sample survey and a situational experiment. Frontiers in Psychology, [S. I.], v. 8, n. 2315, p. 1-16, 2018. DOI: 10.3389/fpsyg.2017.02315

POOLE, W. L. Organizational justice as a framework for understanding union-management relations in education. Canadian Journal of Education, [S. I.], v. 30, n. 3, p. 725-748, 2007.

RAWLS, J. Uma teoria da justiça. 3 ed. São Paulo: Martins Fontes, 2008.

REGO, A. Comprometimento afectivo dos membros organizacionais: o papel das percepções de justiça. Revista de Administração Contemporânea, [S. I.], v. 6, n. 2, p. 209-241, 2002.

REIS, A. L. P. P.; FERNANDES, S. R. P.; GOMES, A. F. Estresse e fatores psicossociais. Psicologia Ciência e Profissão, [S. I.], n. 30, v. 4, p. 712-725, 2010.

RIBEIRO, C. I. M. Cultura organizacional: a relação entre justiça e comprometimento organizacional em uma organização multinacional. 2006. Dissertação (Mestrado em Gestão e Estratégia em Negócios) - Universidade Federal Rural do Rio de Janeiro, Rio de Janeiro, 2006.

SAMPIERI, R. H.; COLLADO, C. F.; LUCIO, M. P. B. Metodología de la investigation. México: McGraw-Hill, 1991.

SCHNEIDER, A. M. M. Características de personalidade em bancários vítimas de assalto. 2011. Dissertação (Mestrado em Psicologia Clínica) - Pontifícia Universidade Católica do Rio Grande do Sul, Porto Alegre, 2011.

SEMBIRING, N.; NIMRAN, U.; ASTUTI, E. S.; UTAMI, H. N. The effects of emotional intelligence and organizational justice on job satisfaction, caring climate, and criminal investigation officers' performance. International Journal of Organizational Analysis, [S. I.], v. 28, n. 5, June, 2020.

SHARMA, H.; YADAV, R. Understanding the relationship between organisational justice and work engagement in banking sector. Journal of Entrepreneurship \& Management, [S. I.], v. 6, n. 2, 2017.

SINGH, S. K.; SINGH, A. P. Interplay of organizational justice, psychological empowerment, organizational citizenship behavior, and job satisfaction in the context of circular economy, Management Decision, [S. I.], v. 57, n. 3, Dec. 2018.

SIQUEIRA, M. M. M.; GOMIDE JÚNIOR, S. Vínculos do indivíduo com o trabalho e com a organização. In: ZANELLI, J. C.; BORGES-ANDRADE, J. E.; BASTOS, A. V. Psicologia, organizações e trabalho no Brasil. Porto Alegre: Artmed, 2004.

SOTO, E. Comportamento organizacional: o impacto das emoções. São Paulo: Pioneira Thomson Learning, 2005.

TERZI, A. R.; DÜLKER, A. P.; ALTIN, F.; ÇELIK, F.; DALKIRAN, M.; YULCU, N. T.; DENIZ, Ü. An analysis of organizational justice and organizational identification relation based on teachers' perceptions. Universal Journal of Educational Research, [S. I.], v. 5, n. 3, p. 488-495, 2017. 


\section{Contato:}

Tarízi Cioccari Gomes

E-mail: tarizi@hotmail.com

Vania de Fátima Barros Estivalete

E-mail: vaniaestivalete@ufsm.br

\section{Amanda Oliveira Ramadam}

E-mail: amandaramadam@gmail.com 